\title{
Poesia e crise em Jorge de Lima e Murilo Mendes
}

Sergio Carvalho Assunção

scassuncao@uol.com.br

Universidade Federal Fluminense (UFF)

Rio de Janeiro, RJ, Brasil.
RESUMO

Este artigo visa abordar as poéticas de Murilo Mendes e Jorge de Lima sob a perspectiva da suprarrealidade e da busca da unidade com o sagrado, a partir da evidência de um estado de crise existencial e espiritual que se materializa ao nível do corpo e de suas respectivas linguagens poéticas.

PALAVRAS-CHAVE: Poesia. Crise. Sujeito. Murilo Mendes. Jorge de Lima. 
Eu vi os anjos nas cidades claras,

Nas brancas praças do país do sol.

Eu vi os anjos no meio dia intenso,

Na nuvem indecisa e na onda sensual.

Murilo Mendes

Ainda que o enfoque da temática nacional modernista tenha sido predominante na primeira fase da poesia de Murilo Mendes e Jorge de Lima, a modernidade que efetivamente caracterizou suas respectivas produções transcendeu não só a esfera culturalista da geração de 1922, como foi muito além da tonalidade crítica social da geração de 30 . Guardadas as devidas produções, podemos dizer que ambos abordaram o sujeito do século XX através de uma perspectiva universalista, ao adentrar o lugar do sagrado a partir de uma inquietude vivenciada ao nível do corpo desse mesmo sujeito, além de apropriarem-se de procedimentos técnicos absorvidos das vanguardas europeias como solução formal para expressarem a dimensão suprarreal em suas respectivas linguagens poéticas.

Sabemos que a poesia de Murilo Mendes e Jorge de Lima foi determinantemente potencializada pela evidência de um estado de crise existencial e espiritual, acentuado pela euforia desenvolvimentista industrial, pelo materialismo decorrente desta lógica e culminado pelas guerras mundiais e o colapso econômico. Através da poesia, este estado de crise foi trazido à tona, na medida que a experiência poética deixava de ser apenas um modo de resistência e intervenção à lógica industrial, tornando-se, sobretudo, o modo pelo qual ambos passaram a cultivar a busca da unidade com o sagrado.

\author{
Os outros que lutem para possuir o mundo \\ Quanto a mim, quero ver-te face a face. \\ Aguardo tua última vinda, \\ Minha forma definitiva e perfeita, \\ Minha justificação na tua unidade (MENDES, Antecipação)
}

No ano de $1935^{1}$, em meio à prolífica "modernização" da poesia brasileira iniciada em 1922, e movidos pela poesia beatífica e espiritual que visava "restaurar a poesia em Cristo", os poetas Jorge de Lima e Murilo Mendes lançaram juntos o livro Tempo e Eternidade, que consideramos ser o ponto divisório e determinante de suas produções, uma vez que foi a partir dele que a perspectiva da analogia foi definitivamente consolidada em suas obras subsequentes. Além deste fato, o livro serviu como um contraponto ao modelo de poesia legitimado pela crítica 
especializada que se estabeleceu como dominante em nosso cenário, desde o livro Pau Brasil, de Oswald de Andrade, caracterizado pelo poema piada, pela compactação da linguagem e pelo engajamento social.

Ainda que o processo de industrialização tenha provocado efeitos irreversíveis na concepção do homem moderno do século XX, ao acelerar o tempo e desdobrar os espaços, mantendo-os imanentes e interconectados, era preciso superar a concepção que reduzia a poesia moderna brasileira a um paradigma que a colocou a serviço da forma, apenas como 'produto para consumo', segundo a visão centralizadora de Oswald e seus epígonos.

Em contrapartida, muito embora a religiosidade tenha sido determinante para a concepção artesanal de Jorge e Murilo, isso não significou que suas poesias adotassem uma expressão puramente ascética ou proselitista. Ao contrário, ambas as poéticas se valeram essencialmente da elevação metafísica e espiritual, mas sempre a colocando sob permanente tensão com a desordem material da vida cotidiana e, sobretudo, vivenciando-a ao nível do corpo e da sensibilidade.

Diante da evidência de uma existência em crise provocada pela desumanização do progresso industrial e pela beligerância das guerras, a poesia de Murilo Mendes expõe o limite e a impotência da razão humana diante do vazio espiritual e da miséria social. Na medida em que sua poesia coloca o insólito e o absurdo ao mesmo nível da vida cotidiana do sujeito, ela visa, dessa maneira, libertar o imaginário da perspectiva ordinária e materialista, lançando-o ao onírico, além de expressar o anseio pela promessa da vida eterna, sob a égide da natureza infinita de Deus.

\section{$[\ldots]$}

Vim para sofrer as influências do tempo

E para afirmar o princípio eterno de onde vim.

Vim para distribuir inspiração às musas.

Vim para anunciar que a voz dos homens

Abafará a voz da sirene e da máquina,

E que a palavra essencial de Jesus Cristo

Dominará as palavras do patrão e do operário.

Vim para conhecer Deus meu criador, pouco a pouco,

Pois se O visse de repente, sem preparo, morreria. (MENDES, 1994, p. 248-9)

Davi Arrigucci (2000) diz que se tentarmos reduzir a poética de Murilo apenas ao aspecto religioso, cometemos um erro, justamente por ignorarmos as múltiplas dimensões e metamorfoses que perpassam sua poesia.

Para ele, a busca da unidade essencial da poesia de Murilo só pode ser feita através da analogia que, na medida harmoniosa de seu ritmo universal, torna possível a fusão dos contrários e dos elementos díspares que assinalam o mundo focalizado pela lente dialética do caos e da glória. Seja pela dicção que funde a coloquialidade à erudição, do tom filosófico ao jocoso, seja pela dialética da 
materialidade da vida e sua elevação espiritual, ele afirma que somente pelo viés da analogia que Murilo pôde dar unidade formal ao desequilíbrio paradoxal da modernidade, marcada pela experiência vivencial do sujeito em permanente desconcerto com o mundo. Sob a perspectiva harmoniosa da analogia, o terrível conjuga-se com o fantástico, o mundano com o celestial, e a instantaneidade do tempo histórico desemboca na plenitude da eternidade.

Ainda segundo Arrigucci (2000), a analogia serviu tanto como uma perspectiva espiritual, quanto solução estética na poesia de Murilo Mendes, em sua artesania de registrar o caos e as contradições da experiência humana na modernidade industrial do século XX. Sua linguagem poética se amolda na soldagem das imagens desconexas, suscitando um ritmo próprio, marcado pela intermitência do contratempo entre o efêmero e o eterno, proporcionando, assim, a harmoniosa unidade dos contrários.

\begin{abstract}
A analogia parece uma solução instantânea para o problema formal, pois permite descobrir, num átimo, uma imprevista harmonia em meio ao desconcerto geral das coisas. A idéia de uma harmonia feita de tensões é cara à sensibilidade moderna, e Murilo explorou-a ao máximo. Desse modo, por via analógica, a sua sensibilidade, identificada com essa percepção da harmonia tensa dos contrários, retoma uma das mais velhas idéias da tradição ocidental, desde os gregos: a da harmonia do mundo, correlata do sentimento de fragmentação e dispersão do sentido que abandona o universo desencantado e em si mesmo contraditório da modernidade. [...] A modernidade torna-se constitutiva da perplexidade do poeta e também de sua busca de solução formal. (ARRIGUCCI, 2000, p. 98)
\end{abstract}

Entretanto, ainda que a harmonização defendida por Davi Arrigucci tenha servido como solução expressional na poesia de Murilo, há uma tensão que ultrapassa os contornos da plasticidade e transborda das imagens, eclodindo o acirramento e a complexidade da natureza humana sob múltiplas dimensões fragmentárias que compõem a unidade dramática de sua poesia, corroborando com a experiência agônica do sujeito moderno, ao revelar sua angústia diante da ausência de sentido e o ávido desejo por um sentido primordial que justifique sua existência e supere seu desencanto.

Ao mesmo tempo em que o poeta traz para a superfície do corpo as sensações despertadas pelo desejo, é capaz de elevá-las à transcendência, movido pela crença e pela consciência que reconhece a condição humana como aquela que persegue a gloriosa harmonia, embora vivendo em meio ao caos, à descontinuidade e desconcerto entre o corpo e a alma.

Consequentemente, uma das constantes marcas da poesia de Murilo é traduzida pelo efeito de inquietude provocado pela sensualidade feminina em contraposição à religiosidade. Novamente, o desalinho do sujeito em relação ao mundo é trazido à tona, vivenciado pela tensão entre a volúpia ardorosa dos impulsos carnais e a busca de elevação espiritual, como se este dilema constituísse o 'doce enigma' de morrer e viver, libertando-se da angústia do pecado e da carne para se alcançar a eterna vida do espírito. Por outro lado, o poeta tem a consciência de que o acirramento entre o desejo carnal e espiritual pela mulher amada é da própria natureza amorosa humana e sua sacrificial consubstanciação. 
Desta angústia do pecado e da carne.

De ti, contigo e por ti é que eu vivo.

Julgamento, inferno e paraíso:

Sois menos necessários ao poeta.

A minha morte

É também a morte de todas as mulheres que existem comigo,

Aquela que eu amo e não me ama,

Aquelas que eu não amo e me amam.

Morte, salário da vida.

Doce enigma da morte. (MENDES, 1994, p. 306-7)

Seja ainda pelo viés sensual, erótico ou materno, seja pela perspectiva mítica, idealizada ou religiosa, a figura da mulher está presente em toda a obra de Murilo, sem que em momento algum ela represente o pecado original que condena o poeta em forma de culpa, ameaçando sua salvação. Absolutamente, a mulher é sempre o enigma que o coloca na fronteira entre o eu e o outro, entre o real e o sonho, entre o corpo e a alma, entre o terreno e o celestial, ao ser desejada pelos sentidos, pelos instintos e pela paixão, ao mesmo tempo em que é sublimada pelas formas perfeitas, pelo amor e pela divina criação.

No entanto, movido pela ótica cristã, o poeta sabe que esse estado agonístico que se passa ao nível do corpo e sob a consciência angustiada, faz parte da própria condição humana no mundo. Ou seja, é preciso resistir ao ímpeto instintivo dos desejos, considerando, sobretudo, que sua consciência e fé em Cristo não estão puramente no alheamento de uma paz perene, mas, ao contrário, estão na luta diária e no anseio de transformação e fortalecimento espiritual através das tribulações vivenciadas no cotidiano, tal como está anunciado desde o livro Bíblico da Gênese 4:7, que "o seu desejo será contra ti, mas a ti cumpre dominá-Io", ou pelo próprio Cristo no Evangelho de João 16:33, onde diz que "No mundo tereis aflição, mas tende bom ânimo".

Em outras palavras, o poeta sabe que Deus não traz apenas a paz, mas a guerra, a divisão, o conflito, o drama, a crise, configuradas desde a vulnerabilidade do corpo até a consciência angustiada que tenta se libertar de uma razão materialista e secular, ao vislumbrar a existência pela perspectiva dialética, enigmática e espiritual. Isto é, o poeta reconhece que a experiência humana é movida por um paradoxo vivenciado entre a imanência natural do pecado e a transcendência sobrenatural do sagrado, transubstanciando-os na matéria verbal de sua linguagem poética.

Foram nas palavras de Laís Corrêia de Araujo (2000) que encontramos a melhor tradução para este estado metanoico vivenciado por Murilo em sua experiência com a palavra poética e beatífica, ao expressar o amor como absoluta manifestação do sagrado. 
linguagem do poeta cede lugar à diafania, à percepção da onipresença do Amor, em suas encarnações impetuosas e híbridas. (ARAUJO, 2000, p. 86)

Ainda que a autora se refira às diversas mulheres citadas em no livro $A$ poesia em Pânico, publicado em 1936, é possível identificar a temática do amor como elemento essencial em sua obra, em interface com a crise espiritual.

Para o poeta, ao mesmo tempo que sua poesia é deflagrada pela crise e pela ameaça de desencanto, é também potencializada pelo amor, uma vez que o considera como o único sentimento humano capaz de superar a angústia existencial e preencher o abismo espiritual que corrói o sujeito. O amor transfunde, dialeticamente, as esferas do corpo e do espírito, e do eu com o outro, em unidade com Deus, seja na forma do Eros manifestado nas diversas personagens femininas, seja sob a forma do Ágape da caridade e da compaixão pelo próximo.

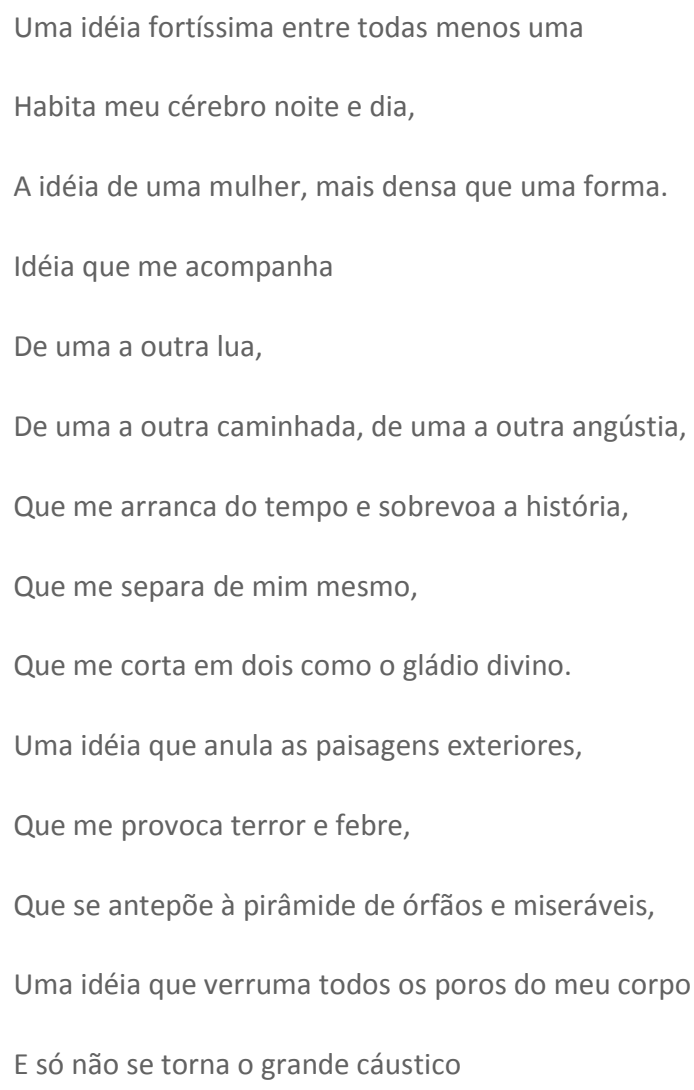

Se as semelhanças entre Murilo Mendes e Jorge de Lima passam pela conversão religiosa, pela dimensão onírica e mitológica fundidas à dimensão do sagrado, além da potencialização da crise espiritual como eixo dinâmico de suas poéticas, desde antes do livro Tempo e eternidade, que escreveram juntos e publicaram em 1935, suas diferenças giram em torno das singularidades de suas respectivas linguagens no que diz respeito à matéria expressional. 
Em Jorge de Lima, ainda que a expressão de sua poesia passe formalmente pela tensão irreconciliável do homem e sua existência, só é possível compreender sua analogia ao situá-la a partir do eixo cristocêntrico do Evangelho. Afinal, o poeta expressa a condição humana daquele que reconhece a presença do sagrado em sua vida. Ou seja, ele fala do homem que é capaz de reconhecer sua precariedade e suas limitações, ao mesmo tempo que está seguro do seu poder de transformálos, movido pelo poder da fé e fortalecido pela abnegação, ao renunciaros pecados do mundo e superar as tribulações do corpo, como modo de elevação do espírito.

Sinto-me salivado pelo Verbo,

rodeado de presenças e mensagens,

de santuários falhados e de quedas,

de obstáculos, de limbos e de muros.

Furo as noites e vejo-te, Solstício,

ou recolho-me ao âmago das coisas,

renovo um sacrifício expiatório,

lavo as palavras como lavo as mãos.

Esta é a zona sem mar e sem distância,

Solidão, sumidouro, barro-vivo,

barro em que reconstruo sangues e vozes.

Não quero interromper-me nem findar-me.

Desejo respirar-me no Teu sopro,

aparecer-me em Ti, continuado. (LIMA, 1997, p. 572)

Ao abordar a poética de Jorge de Lima, Murilo Mendes destaca a importância determinante da incorporação da técnica de fotomontagem dadaísta e surrealista para a construção da linguagem poética de Lima. Ao ampliar a condição humana corpórea e existencial à esfera histórica e social, universal e metafísica, Lima utiliza tal recurso como solução formal para lidar com a simultaneidade de planos convergentes em sua criação. Além disso, sua linguagem assume um caráter barroco que funde as paisagens utópicas sob o tom profético e parenético, produzindo uma realidade onírica e delirante que se eleva à sobrenaturalidade do sagrado, visando a unidade em Cristo.

Além do efeito alucinatório proporcionado pelo recurso das fotomontagens em sua linguagem, o poeta afixa o caráter transitório da existência, ao recortar o insólito e soldá-lo na esfera do cotidiano, elevando-o a uma nova dimensão, mítica 
e maravilhosa que converge com o sagrado e sobrenatural, ao retirar o tempo da moldura cronológica e secular e abolir as fronteiras da espacialidade objetiva, estendendo-as ao infinito e à eternidade.

Para dominar a desordem que se opõe à construção do insólito monumento, arma-se o poeta de uma tesoura de condão, e fazendo cortes implacáveis no tempo, obtém uma dimensão nova. [...] E o tempo se faz reconstruído não apenas pela fotomontagem da infância, como também pela contínua referência da Queda do homem, cujo processo se desenrola no transcurso da história. O espírito luciferino acena-lhe com o domínio das coisas nascidas da carne e do sangue, mas o espírito que santifica as raízes do mundo propõeIhe a escolha, a opção, a renúncia dos elementos efêmeros. Entretanto, não adianta renunciar o efêmero sem saber os valores que ele traz consigo. A solução do problema, segundo me parece, é esta: fixar o efêmero, suas formas mutáveis, suas categorias estéticas e sociais, e transcendê-lo. (LIMA, 2013, p. 516-7)

No mundo civilizado, quanto mais o homem é esmagado pelas estruturas sociais, reduzido ao individualismo e à competitividade, mais ele passa a ser preenchido pelo vazio, que é causado pela ansiedade, pela angústia e frustração. Certamente que essa condição se acentua na modernidade industrial do século XX, de modo que o homem civilizado é marcado pelo signo da opressão, pela moratória ilimitada e pela desumanização, ao ser robotizado e reduzido a um objeto, a uma estatística ou função produtiva.

Em face desse processo maquínico, o poeta expõe sua consciência, acirrada pela moral social que regula e oprime o indivíduo, mas que opta pela libertação espiritual da teologia cristã. Logo, a poesia de Jorge de Lima revela não apenas um mundo ilusório, mas também uma consciência em crise, dimensionada em seus poemas por um profundo sentimento de fraternidade universal e cultivo espiritual. Contra esse vazio que condena o sujeito, cada vez mais, à solidão estéril e materialista, o poeta cristão anseia libertar o indivíduo por meio de sua poesia voltada para a graça divina.

Segundo Murilo², sobre a poesia de Lima:

O que se acha em jogo [...] é a própria condição do homem, sua subsistência no presente e no futuro. A questão social transformou-se na questão mesma da humanidade. [...] Há em primeiro lugar a divisão do homem dentro de si próprio: a consciência desta divisão estende-se a todos. [...] Opera-se uma revisão total das possibilidades do homem em face da natureza e do desconhecido. $O$ poder político - penso particularmente no poder totalitário - é um dos personagens principais do drama: agravamento do terror, tentativa de exoneração do humanismo, eliminação das nossas tendências místicas e contemplativas, apelo à única força telúrica, e supressão da nossa intimidade fecunda para se criar, através de monstruosos métodos científicos, uma solidão estéril e desumana - o que determina o aparecimento de uma nova espécie de homem, o homem mecânico, o homem robot, o homem sozinho em face de um Estado e de um universo hostis, fautores de um permanente estado de sítio. (LIMA, 2013, p. 527-8)

Entretanto, torna-se imprescindível abordar a experimentação poética criada por eles, cada qual à sua maneira, entre o surrealismo e o sagrado na tentativa de reconhecer os procedimentos pelos quais se transubstanciaram a analogia e a cultura na poesia de Jorge de Lima e Murilo Mendes. 
Assim, ao nos referirmos aos procedimentos técnicos utilizados pela vanguarda surrealista, nos perguntamos então sobre qual surrealismo estamos nos referindo? Ao surrealismo da escrita automática e da exaltação do sonho, do Primeiro Manifesto do Surrealismo ${ }^{3}$, de André Breton? Ao surrealismo anárquico e iconoclasta, mas que se tornou dogmático e ideológico, quando Breton se aproximou do comunismo e contrariou o espírito libertário inicial? Ou seria o surrealismo dissidente de Antonin Artaud, que se aproxima da analogia com o sagrado, pela sua experiência com o xamanismo?

Sobre a poética de Jorge de Lima, José Niraldo de Farias afirma:

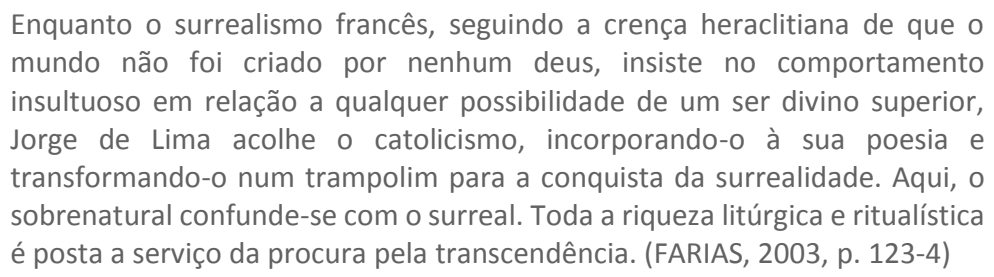

Consideramos que, em ambos os poetas e, cada qual ao seu modo, a experimentação plástica da palavra que nos conduz ao surreal vislumbra, ao mesmo tempo, aproximar-nos da transcendência sobrenatural do sagrado pela voz profética, constituindo, assim, uma dimensão poética e beatífica que nos revela a suprarrealidade metafísica do que chamamos de "poética do sagrado".

A observação de Niraldo pode ser corroborada pelas palavras de Murilo Mendes:

\begin{abstract}
Abracei o surrealismo à moda brasileira, tomando dele o que mais me interessava: além de muitos capítulos da cartilha inconformista, a criação de uma atmosfera poética baseada na acoplagem de elementos díspares. Tratava-se de explorar o subconsciente; de inventar um outro frisson nouveau, extraído à modernidade; tudo deveria contribuir para uma visão fantástica do homem e suas possibilidades extremas. (MENDES, 1994, p. 1238-9)
\end{abstract}

Nesses termos, podemos dizer que tanto em Jorge de Lima quanto em Murilo Mendes, a transcendência resulta de uma concepção poética que se origina na pintura surrealista, ao abranger elementos dissonantes que são justapostos no texto, pela apropriação dos recursos das colagens ou fotomontagens. A fusão desses contrários potencializa uma concepção inteiramente nova, que visa a acolher o espírito pela evasão metafísica, através da realidade analógica do sagrado, que se eleva pela percepção surpreendente e visionária do infinito, dimensionando uma suprarrealidade.

Sob outro aspecto, essa dramaticidade revela, em ambos, o caráter conflituoso do homem moderno, considerando que as respectivas poéticas transitam do cotidiano social, elevado à perspectiva imaginária, mítica e onírica, pela dimensão metafísica, espiritual e inefável da analogia em correspondência com o sagrado, eterno e sobrenatural, de modo que só a poesia proporciona tal experiência de unidade entre o suprarreal e o supranatural.

Mais uma vez, enquanto em Murilo Mendes a linguagem atinge um equilíbrio mais conciso na justaposição das imagens dissonantes, em Jorge de Lima a linguagem se acirra sob um tom ondulante, febril, suscitando um estado delirante 
que anseia pela glória divina, mas que se encontra preso à terrena condição, desde a herança do pecado adâmico e da queda, à esperança de remissão.

Sua linguagem poética é marcada por um barroquismo que incorpora os elementos fragmentários e heteróclitos, mesmo quando se encontra sob a cadência do verso metrificado, consubstanciando-os nas imagens que evocam uma atmosfera angustiante de irresoluta embriaguez, lutando entre a luz e a treva, pela divina salvação.

“Glória a Deus nas alturas, paz na terra!"

Mas outras vozes graves vinham logo

Abafar o divino capitel

Que na garganta ínfima era um gole.

\author{
A luz estertorava sob o fole \\ De desvairado sapo; e em charco gela \\ O que é luz do Senhor. Povoa-me a ópera \\ De anjos executados como réus.
}

Amargada paixão sem glória e quírie,

Só para moer o joio fementido

Ou remar nas galés vociferantes;

Só para estrangular as vozes pias

Das aleluias. Glória ao pai, ao Filho

E ao Santo Espírito - a ázima canção. (LIMA, 1997, p. 884-5)

Evidentemente que o efeito das técnicas experimentais de fotomontagem e o caráter pictórico da linguagem poética possam ser atribuídos ao fato de o poeta Jorge de Lima ter sido também pintor e profundo conhecedor das artes modernas, lançando, inclusive, um livro de fotomontagens, chamado $A$ pintura em pânico (1943). Tanto que, em entrevista a Homero Sena, em 1945, ao ser questionado sobre as linguagens da arte a que se dedica, o próprio poeta alagoano, declara sua predileção: "- Prefiro a poesia. Tudo o mais que tenho tentado, inclusive a pintura, está subordinado ao sol da poesia, são caminhos para ela, às vezes simples exercícios para conferir-Ihe novas dimensões, outras profundezas." (LIMA, 1997, p. 91).

Embora ambos tenham assumidamente absorvido as técnicas de Giorgio de Chirico, Max Ernst, René Magritte e o próprio André Breton, entre outros, a aproximação de Murilo Mendes com o surrealismo ocorreu, definitivamente, a 
partir do contato com seu amigo Ismael Nery. Foi por meio da amizade e do contato com Ismael, Murilo tomou conhecimento da sua teoria essencialista que, certamente, influenciou a concepção poética do poeta mineiro, ao fundir a arte e o evangelho. Em suas palavras, Murilo afirma que o "essencialismo" foi uma teoria filosófica criada por Ismael Nery, baseada na abstração do tempo e do espaço, na seleção e cultivo dos elementos essenciais à existência, visando ao absoluto, ao essencial e à unidade entre o homem e Deus por meio do evangelho e da arte.

Ismael tinha apenas 25 ou 26 anos de idade, e já os seus próximos sabiam que havia construído um sistema filosófico muito original, apesar de o não escrever. Era o essencialismo, baseado na abstração do tempo e do espaço, na seleção e cultivo dos elementos essenciais à existência, na redução do tempo à unidade, na evolução sobre si mesmo para a descoberta do próprio essencial, na representação das noções permanentes que darão à arte a universalidade. (MENDES, 1996, p. 65)

Deste modo, talvez seja pertinente consideramos a hipótese de que as poéticas espirituais e surrealistas de Murilo Mendes e Jorge de Lima aproximamse do "essencialismo" de Nery, visto que suas poéticas cultivam a unidade absoluta entre poesia e sagrado, repudiando a lógica objetiva e materialista da modernidade industrial que se consolidou como cultura dominante em nossas produções. Antes de se tornar um conceito, um discurso ou instituição, o sagrado é uma experiência vivencial que, para o cristão, deve ser experimentado na vida diária, de modo que o corpo se transforme em um templo vivo, como um receptáculo do Espírito Santo de Deus.

Muito embora Murilo e Jorge assumissem claramente a conversão religiosa o que implica, sobretudo, uma postura ética em suas respectivas poéticas -, em nenhum momento esse fato comprometeu o caráter moderno, crítico e experimental de suas produções. Ao contrário, foi a fusão do tom profético e apocalíptico com a plasticidade surrealista que deu às respectivas poéticas a radicalidade expressional, abrangendo a crítica ao esfacelamento, à degradação e à desumanidade da era industrial e de suas guerras.

Além de uma experimentação da própria materialidade verbal, da criação de uma linguagem e de uma tessitura estética, reconhecemos as poesias de Jorge de Lima e Murilo Mendes como uma experiência ética, vivencial, que potencializa a consciência e a sensibilidade ao dilatar o tempo e o espaço, ao transcender o ato cotidiano sob a perspectiva do sonho, do imaginário, e do sagrado primordial.

Evidentemente, é a partir deste vórtice analógico que as poéticas de Jorge e Murilo atingem sua expressão mais substancial, quando o sagrado é retirado da moldura discursiva e institucionalizada para ser vivenciado sob a experiência estética e cultural, ao expandir o cotidiano a uma suprarrealidade metafísica através da poesia, ao mesmo tempo em que esta é elevada a um saber universal, retornando à sutileza da vida comum e compartilhada com o outro.

\footnotetext{
Porque o sangue de Cristo

jorrou sobre os meus olhos,

a minha visão é universal
} 
Os milênios passados e os futuros

não me aturdem porque nasço e nascerei,

porque sou uno com todas as criaturas,

com todos os seres, com todas as coisas,

que eu decomponho e absorvo com os sentidos,

e compreendo com a inteligência

transfigurada em Cristo.

Tenho os movimentos alargados.

Sou ubíquo: estou em Deus e na matéria;

sou velhíssimo e apenas nasci ontem,

estou molhado dos limos primitivos,

e ao mesmo tempo ressoo as trombetas finais,

compreendo todas as línguas, todos os gestos, todos os signos,

tenho glóbulos de sangue das raças mais opostas.

Posso enxugar com um simples aceno

o choro de todos os irmãos distantes.

Posso estender sobre todas as cabeças um céu unânime e estrelado. (LIMA, 1997, p. 425) 


\title{
The crisis of the subject in the poetry of Jorge de Lima and Murilo Mendes
}

\begin{abstract}
This article aims to approach the poetics of Murilo Mendes and Jorge de Lima from the perspective of a state of existential and spiritual crisis of the subject, through their respective poetic language in modern times of the twentieth century.
\end{abstract}

KEYWORDS: Poetry. Crisis. Subject. Murilo Mendes. Jorge de Lima. 


\section{NOTAS}

1 As obras de ambos os poetas citadas no corpo do texto serão indicadas entre parênteses, respeitando o ano de seus respectivos lançamentos, embora os fragmentos dos poemas citados sejam extraídos das "obras completas" de cada um deles, citadas ao final do texto. A saber: LIMA, Jorge de. Poesia completa. Rio de Janeiro: Nova Aguilar, 1997; MENDES, Murilo. Poesia completa e prosa, volume único. Rio de Janeiro: Nova Aguilar, 1994.

2 Publicado no suplemento "Letras e Artes", de A Manhã, Rio de Janeiro, 24 de junho de 1952. Transcrito no apêndice da primeira edição de Invenção de Orfeu, e reproduzido na novíssima edição de 2013. In.: LIMA, Jorge de. A invenção de Orfeu. São Paulo: Cosac Naify, 2013.

3 In.: TELES, Gilberto M. Vanguardas européias e Modernismo brasileiro. Petrópolis: Vozes, 1978.

\section{REFERÊNCIAS}

ARAUJO, Laís Corrêa de. Murilo Mendes: ensaio crítico, antologia, correspondência. São Paulo: Perspectiva, 2000.

ARRIGUCCI JR., Davi. O cacto e as ruínas. São Paulo: Duas cidades; Ed. 34: 2000.

Bíblia Sagrada. Traduzida em Português por João Ferreira de Almeida. Revista e atualizada. Barueri: Sociedade Bíblica do Brasil, 2011.

FARIAS, José Niraldo de. O surrealismo na poesia de Jorge de Lima. Porto Alegre: Edipucrs, 2003.

LIMA, Jorge de. Poesia completa. Rio de Janeiro: Nova Aguilar, 1997.

. A invenção de Orfeu. São Paulo: Cosac Naify, 2013.

MENDES, Murilo. Poesia completa e prosa, volume único. Rio de Janeiro: Nova Aguilar, 1994.

. Recordações de Ismael Nery. São Paulo: EdUsp, 1996.

TELES, Gilberto M. Vanguardas européias e Modernismo brasileiro. Petrópolis: Vozes, 1978. 
Recebido: 22 jan. 2016

Aprovado: 30 mai. 2016

DOI: $10.3895 /$ rl.v18n22.3695

Como citar: ASSUNÇÃO, S.C. Poesia e crise em Jorge de Lima e Murilo Mendes. R. Letras, Curitiba, v. 18, n. 22, p. 40-54, jan./jul. 2016. Disponível em: <https://periodicos.utfpr.edu.br/rl>. Acesso em: XXX.

Direito autoral: Este artigo está licenciado sob os termos da Licença Creative Commons-Atribuição 4.0 Internacional. 